\title{
How-To Pages: Informal Systems of Expertise Sharing
}

\author{
Cristen Torrey ${ }^{1}$, David W. McDonald ${ }^{2}$, Bill N. Schilit, ${ }^{3}$ and Sara Bly ${ }^{4}$ \\ ${ }^{1}$ Human Computer Interaction Institute, Carnegie Mellon University \\ ctorrey@cs.cmu.edu \\ ${ }^{2}$ Information School, University of Washington \\ dwmc@u.washington.edu \\ ${ }^{3}$ Google Research \\ schilit@google.com \\ ${ }^{4}$ Sara Bly Consulting \\ sara@sarably.com
}

\begin{abstract}
The How-To has recently emerged as a genre of online content that describes how something is done. This study focuses on computer and electronics hobbyists and their use of How-Tos-how hobbyists use existing knowledge to solve technical challenges, how they document their new knowledge for one another, and how they exchange help and feedback. Our analysis describes How-To knowledge sharing as a fully decentralized expertise-location system in which the How-To functions as both a broadcast of the author's expertise and a personal portfolio.
\end{abstract}

\section{Introduction}

Internet technologies have the potential to facilitate knowledge sharing among individuals around the world on every conceivable topic-if experts are able and willing to document their knowledge. Research suggests this is not a straightforward proposition. Experts may not be able to fully articulate what they know (Spender, 1996; Leonard and Sensiper, 1998). Or they may be unwilling to reveal the valuable knowledge they created (Hinds and Pfeffer, 2003). Despite the 
obstacles, an increasingly popular form of procedural knowledge sharing - known as the How-To-has emerged.

A How-To refers to online content that describes how something is done. How-Tos, largely written by volunteers, explain how to install water heaters, how to knit socks, how to pack a suitcase, and on and on. We were intrigued, in particular, by the use of the How-To among computer and electronics hobbyists. These hobbyists generate detailed, step-by-step descriptions of their creative and often time-consuming activities. As just one example, a lengthy How-To describes the process of taking a Guitar Hero video game controller apart and reassembling it inside a full-size electric guitar ${ }^{1}$. (Figure 1 details one step in this process.) The authors of this How-To estimate that the project took them seventyfive hours to complete, and they introduce the How-To by explaining, "it occurred to us that you might enjoy making one of your own."

\begin{abstract}
You'll notice that in some pictures we used a thicker wire in the neck. Originally we thought that this thicker wire would be easier to control, but we later discovered that it lacked the flexibility necessary to fit in the main guitar body cavity. So, we replaced it with a piece of nicely-bundled cat-5 networking cable.
\end{abstract}

\begin{abstract}
Regardless, you can see here that the GH controller's wiring scheme is quite simple: one side of the switches shares a common ground while an individual wire runs from each of the other sides, comprising six wires in total.
\end{abstract}
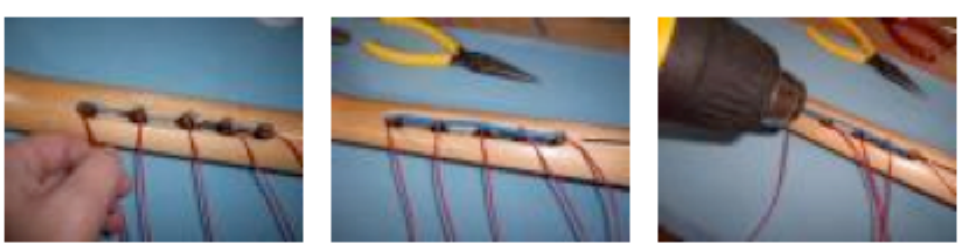

Figure 1. How-To: Build Your Own Custom Full-Sized Wireless Guitar Hero Controller

A knowledge contribution like this is all the more surprising given that computer and electronics hobbyists describe the manipulation of physical objects, which previous research has revealed to be especially difficult in text alone (Pipek and Wulf, 2003). Despite the challenges, hobbyists and their How-Tos appear to be thriving. As far as we are aware, this research is the first to describe How-To knowledge sharing. In this work, we characterize the How-To as a class of online content, and through our study of computer and electronics hobbyists, we provide an initial description of its use and its relationship to other knowledge management practices.

1 http://toolmonger.com/2006/12/05/how-to-build-your-own-custom-full-sized-wireless-guitar-herocontroller/ 


\section{The How-To}

The How-To has become a common format for procedural knowledge sharing. It is a class of online content similar to the FAQ (Halverson et. al., 2004) or the personal homepage. How-Tos can be found online for software usage and modification, hardware and electronics, home improvement, knitting, sewing, woodworking, and many other activities. Numerous websites have attempted to consolidate How-To knowledge into standardized repositories ${ }^{2}$, but How-Tos continue to be published and distributed in diverse ways.

How-Tos are characterized by a sequential description of procedural information. Some How-Tos relate the chronological story of the author's experience, complete with descriptions of the author's mistakes and workarounds. The authors of the Guitar Hero project documented the story of their process with pictures, including successes and frustrations (see Figure 1). In contrast, other How-Tos are written more like recipes, with a list of the necessary tools and straightforward step-by-step instructions for tested task completion (see Figure 2). Plug in USB power, your computer should recognize it as a USB to serial
converter. Drivers are available from FTDI if they don't come with your OS
(most modern ones do)

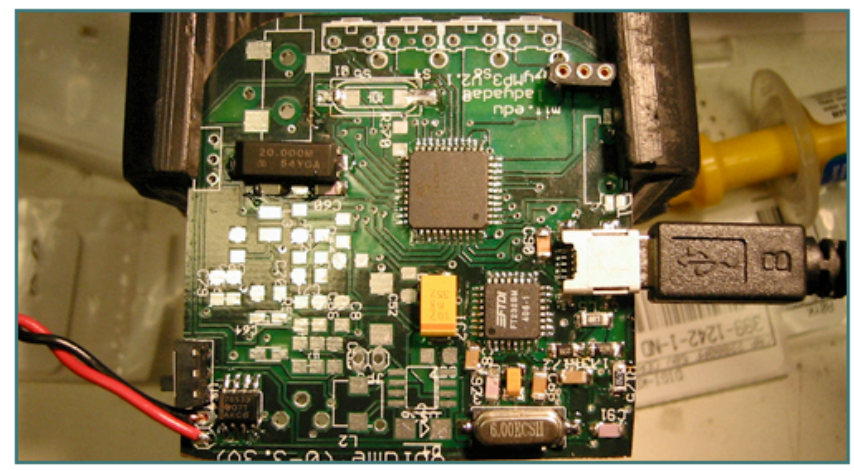

Use the serial driver and tinybld16 (or, if you have decided on a different bootloader, the proper software) to upload the current MintyMp3 firmware. Turn Minty off and on, and use a terminal program (at $1152 \mathrm{Kbps}$ ) to make sure Minty firmware is loaded. It should at least print out "Minty MP3! v2 $3 / 25 / 2004 "$ or something similar

Figure 2. How-To: MintyMP3 Flashing the Firmware

\section{Computer \& Electronics Hobbyists}

Hobbyists work on projects they enjoy. There is no company or professional society which structures their work or organizes their contributions, and yet

2 For example, http://www.instructables.com; http://www.howtopedia.org; http://www.wikihow.com; http://www.howtoforge.com 
content around electronics and computer projects is growing rapidly. The current proliferation of hobbyist-created online content is supported by a related growth in commercial resources like magazines, books, parts, and kits. A successful United States print publication, MAKE magazine, gives detailed instructions for all kinds of do-it-yourself technology. In a recent issue, for example, readers learned how to make biodiesel fuel and how to create ringtones for their cell phones from songs in their music collection. Fairs and conferences give hobbyists the opportunity to display and discuss their work with others. Last year's Maker Faire in San Mateo, California had 20,000 attendees (Goldfayn, 2007). Tools, platforms, and other resources are becoming available as well; an increasing number of hobbyist kits are available for experimenting with technologies like RFID and sensor networks.

MAKE magazine and its extended family of blogs, forums, kits, and fairs refer to hobbyists as makers though elsewhere they may be referred to as enthusiasts, hackers, or modders. In this paper, we do not differentiate extensively between these; we refer to anyone building or modifying electronics or computer equipment as a hobbyist. When we discuss a hobbyist's work, we use the term project because it is the most common way hobbyists refer to their work. Often, a link on a hobbyist's home page collects a set of How-Tos under the header, Projects. A project is the collection of tasks for which the How-To is written.

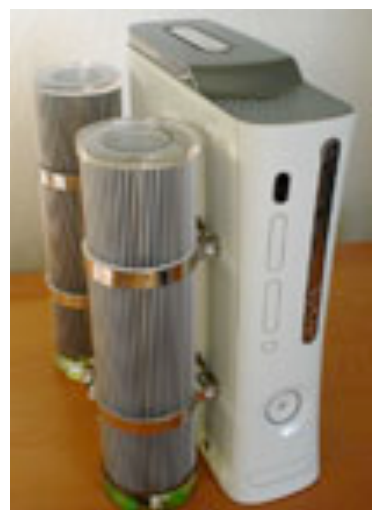

Figure 3. How-To: Xbox 360 WaterCooling Project

Projects have varying objectives. A mod is a modification to an existing product. For example, not long after the Xbox 360 became available, video game enthusiasts found that the device became hot when used for a long time. How-Tos for adding a water-cooling system to the Xbox 360 began popping up in forums and on a variety of websites. The project pictured in Figure 3 is one example ${ }^{3}$. In contrast, other projects are built completely from component parts. Frequently, a hobbyist will mimic the functionality of a commercial product because the product can be built more inexpensively than it can be bought, although building 
it often requires specialized skills. For example, several hobbyists have built their own versions of the expensive Segway scooter with off-the-shelf parts and open source software code. The MintyMP3 project, introduced in Figure 2, is built from off-the-shelf parts and an Altoids tin ${ }^{4}$ (see Figure 4). Another subset of projects combines off-the-shelf parts, and possibly commercial products as well, to create a new product with functionality that is not available to the consumer. Home automation projects, for example, may include lighting, climate, and audio control specifically customized to the hobbyist's needs.

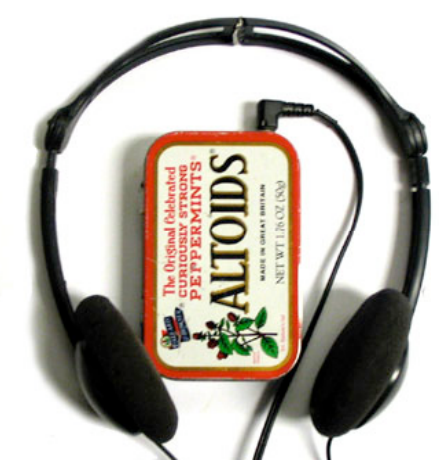

Figure 4. How-To: MintyMP3 Completed

Communicating how something is done can be difficult, particularly when describing how physical objects are manipulated. Computer and electronics hobbyists adopt emerging technologies, from streaming video to 3D modeling software, to improve their ability to communicate process knowledge. Hobbyists link to podcasts, videos hosted on YouTube, 3D models created in Google SketchUp, circuit diagrams, schematics, and usually lots and lots of pictures. The schematic in Figure 5 was posted in a How-To for a one-handed Xbox controller the author designed for a user with a disability 5 . In the How-To, the author describes his design process, makes the schematic available, and specifically asks other hobbyists to develop the idea further. As sophisticated users, hobbyists are in the unique position of making use of a range of existing technologies or, if the solution does not yet exist, building the solution themselves. In observing the online behavior of electronics and computer hobbyists, we are observing a group that feels very comfortable on the Internet and with Internet communication tools.

4 http://www.ladyada.net/make/minty/fabrication.html

5 http://benheck.com/Games/Xbox360/controls/1hand/singlehandcontroller.htm 


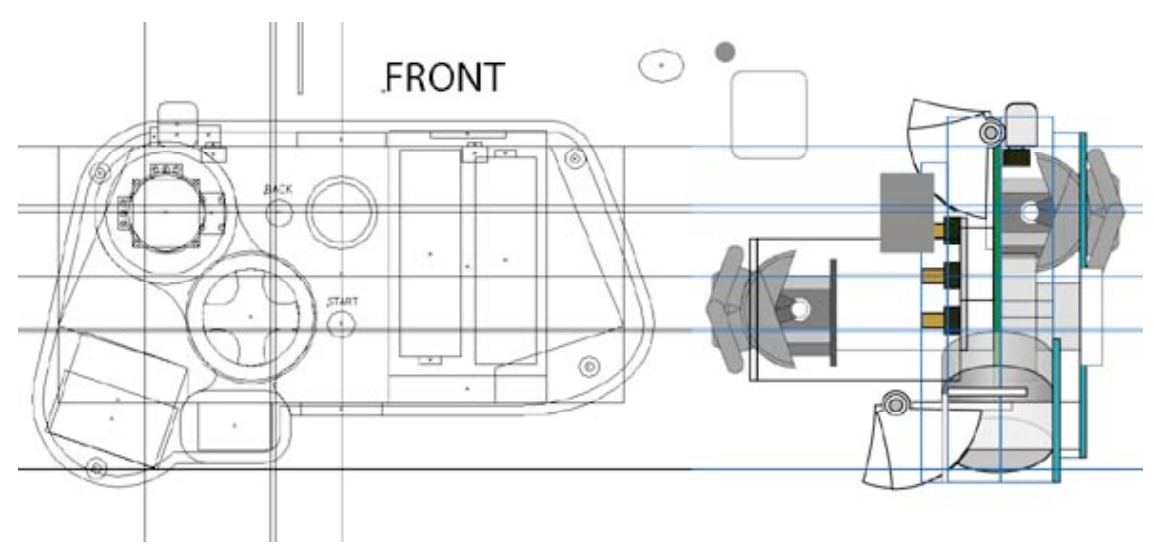

Figure 5. Schematic for Single-Handed Xbox Controller

\section{Method}

In order to observe the activities of hobbyists from their viewpoints and in their own words, we invited hobbyists to participate in individual semi-structured interviews. Our first objective in these interviews was to get a sense for what their work was like - how a project got started, completed, and written up as a HowTo-paying particular attention to the practices and tools they use. Our second objective was to explore the values that motivate these practices, as well as choices of tools. In our analysis, we used our participants', as well as other hobbyists' project documentation as data. In particular, we contextualized participant interviews with a descriptive analysis of participants' How-Tos, and any public communication about the project posted to relevant blogs and forums.

Interviews were conducted over instant messenger or the telephone, whichever participants preferred. The interviews lasted between one and two hours. We conducted eleven interviews over instant messenger and one interview over the phone. The interview conducted over the phone was transcribed for analysis. Our experience with interviewing over instant messenger was similar to that described by Voida et. al. (2004). Frequently, participants would take time responding to our questions. We received some rather reflective responses as a result, but we could potentially be disadvantaged by not being able to observe participants' immediate, perhaps less censored, reactions.

The interviews were focused around a specific project the participant had recently completed and documented. We began by discussing how the project got started and whether the participant had sought help while working on the project. We asked participants who worked primarily alone if they had ever collaborated on a project before or if they wanted to collaborate with others in the future. In following questions, we explored how and why they chose to document their projects. We asked hobbyists who published their How-Tos on their personal 
websites whether they had considered publishing to a forum or a wiki. We then asked participants about any responses they might have received to their project documentation and how they felt about those responses. The interview concluded by asking participants who they thought was reading their documentation and how they felt about their work being used or copied by others.

\section{Participants}

We solicited hobbyists based on posts to popular blogs, such as hackaday, hackedgadgets, and the blog associated with $M A K E$ magazine $^{6}$. We used the project selections of blog editors as our starting point for recruitment in order to locate projects judged to be relevant and useful by hobbyists themselves. Editors of these blogs comment on and link to How-Tos published online by other hobbyists. Often editors will summarize a project and provide a link to the documentation. Readers can interact by adding comments to posts within the blog. Using the hobbyists' documentation, we contacted them directly using any contact information the hobbyist provided. We focused on recent project posts because we believed it would be easier for hobbyists to give specific details about projects that were recently completed.

\begin{tabular}{|l|l|l|l|l|l|}
\hline ID & Gender & Age & Location & Occupation & Sample Projects \\
\hline A & Male & 18 & USA & Student & Headphones, Car Stereo \\
\hline B & Male & 27 & USA & Student & Video Camera Accessory \\
\hline C & Male & 32 & Netherlands & Engineer (Telecom) & Digital TV Display \\
\hline D & Male & 23 & Canada & Software (Finance) & Xbox, Microcontroller \\
\hline E & Male & 26 & USA & Student & Radio, Xbox \\
\hline F & Male & 20 & USA & Student & Robotics, Home Automation \\
\hline G & Male & 24 & Denmark & Student & DVD Player, Digital Cable \\
\hline H & Male & 33 & USA & Software (Telecom) & Camera Accessories \\
\hline I & Male & 35 & UK & Software (Finance) & Radio, Clock, iPod \\
\hline J & Male & 28 & USA & $\begin{array}{l}\text { Software } \\
\text { (Self-employed) }\end{array}$ & Digital Cable Box, Cell Phone \\
\hline K & Male & 25 & USA & Software (University) & Home Audio Network \\
\hline L & Male & 24 & USA & Engineer (Biotech) & Clock, Lighting \\
\hline
\end{tabular}

Table I. Background Information about Interview Participants

Table I summarizes basic information about our participants. Eight participants who accepted our invitation live in the United States; the remaining four participants live in Canada, Denmark, the Netherlands, and the United Kingdom.

6 http://www.hackaday.com; http://www.hackedgadgets.com; http://www.makezine.com/blog 
We encountered a very limited number of How-Tos written by female hobbyists; consequently, all twelve of our participants were male. They ranged in age from late teens to mid-thirties. Our participants were involved in a diverse selection of projects with a range of different devices and technologies ${ }^{7}$.

\section{Findings}

The activities of hobbyists include the retrieval of knowledge, as hobbyists work through problems, and the creation of knowledge, as hobbyists document their solutions. The general structure of our interview accounted for building a project and writing the How-To, but it quickly became clear that the How-To was not the only mechanism for hobbyists' interaction. We found that as hobbyists' retrieve knowledge from websites or other How-Tos they often engage in conversation with other hobbyists. Similarly when a How-To is published, hobbyists participate actively in public and private conversations with others about the completed work. Following Huysman and de Wit (2003), we refer to this activity as knowledge exchange. Knowledge exchange occurs directly between individuals without the mediation of the How-To or some other form of documentation. In our findings, we refer to knowledge exchange, retrieval and creation as specific instances of knowledge sharing behavior.

The presentation follows the lifecycle of a project by addressing hobbyists' goals: building their projects, documenting their stories, and broadcasting their contributions. Our use of the terms, project, story, and contribution, is meant to signify how the nature of the work is transformed by each step in a knowledge sharing process. The project is a challenge the hobbyist has accepted. When that challenge is met, the hobbyist tells the story with words and pictures, and the story becomes a part of the hobbyist's portfolio. Finally, that story becomes a contribution when it is recognized by and becomes a resource for other hobbyists. As hobbyists pursue each goal in turn, they may be engaged in knowledge retrieval, knowledge creation, knowledge exchange, or some combination. In the following, we describe these practices in detail, as well as the technological tools and the motivations for using these tools.

\section{Building their Projects}

Before a hobbyist can invest their time and effort in a project, there must be inspiration. Our interviews revealed a number of different ways that a project

7 By design, hobbyists' projects are quite unique. As such, we will not describe the projects of our participants in great detail as that would indirectly identify them to anyone willing to do a quick internet search. When we describe projects in detail in this paper, we are using comparable examples and not describing the projects of our participants. 
might get started. Ideas for projects can be sparked by problems the hobbyist faces, such as a commercial product that did not come with a remote control.

most of the stories we come up with are a result of figuring out a solution to a problem that we were personally wanting solved - Participant $\mathrm{J}$

A hobbyist may focus on a particular device, like a radio, that they would like to learn more about. The functionality of commercialized products is also a potential starting point for hobbyists who then add functionality or build the product cheaper than it can be bought. One participant started his project "because they just don't make what you want." Several participants subscribe to RSS (Really Simple Syndication) feeds of their favorite blogs to stay informed of new project documentation, new commercial products, and news about technology. Participants freely acknowledge their use of ideas they had first seen in other people's projects.

I generally read those sites and often get ideas from seeing how other people have used technology in interesting ways - Participant F

Several participants' projects were inspired by knowledge about what others were doing. Two of our participants' projects were derivations of someone else's work; each was an attempted improvement on the particular implementation of another hobbyist. Other participants used the work of others more generally to inform their own work on projects with very different goals.

Discovering information via blogs is often a passive retrieval strategy. Our participants were often not specifically looking for the information that inspired them. As a project idea is formed, participants use more active retrieval strategies. Some of the projects described in the interviews were clever but fairly straightforward ideas that were implemented quickly and did not involve a lot of research. Other projects were more difficult, and participants were clear about their desire to reuse information if it was available in order to focus their energies on making something new. Participants reported searching forum archives, manufacturer documentation, Wikipedia, and anything they could find on the Internet. One participant said he was "always reading online," usually project documentation written by other hobbyists that he found by searching the web. Another participant referred to the Internet as a "vast brain-trust" and a "massive card catalog." This participant was not intimidated by the overwhelming amount of information his language implies and spoke optimistically about how great it was to be able to find just the information he was seeking.

i'd be a lot different if it weren't for PCs and the internet it's like an endless library someone will say "i wish i knew what that means..." and i'll promptly suggest we look it up online which seems so foreign to some, but to me it's 2 nd nature ... i've learned volumes more online under my own curiosity than i ever did in school - Participant E

Participants spoke positively about searching for information with Google. After mentioning help received from a colleague, another participant said, "and of course : google is my friend too." 
Google is not the sole method of information seeking that these participants use. In addition to knowledge retrieval, our participants sought out interactions that are better described as knowledge exchange. Half the participants routinely connect to communities of other hobbyists, either face-to-face or online. Some participants identified face-to-face contacts as the source of their support and advice when they were trying to solve a problem for a project. This was often true for participants working within a university environment where a like-minded community had formed, such as within an engineering program. Two participants specifically implemented community features on their personal websites so that friends, as well as visitors, could interact around their website content.

Other participants had ongoing relationships within an online forum or newsgroup that they used for targeted technical advice. Online hobbyist forums are organized with varying degrees of scope. Forums exist for people working on specific devices like a TIVO, a general category of interest like digital audio, or even a more general domain like electronics. Regardless of the specificity of the community's interests, interview participants spoke about being active in online forums where they felt comfortable among the other people.

It is a mature place where you don't have to worry about being called a 'newb' when you ask a question and people always try their best to help you out. - Participant A

When asked about getting help, participants talked about their connections with other people, either face-to-face or online.

we are a group of 4-5 "die-hards" that are really good and interested in microcontroller matters. I talk to them a lot and am very thankful knowing them - Participant G

Participants acknowledged the value of support from other hobbyists, referring to their community members affectionately with terms such as "geeks," "freaks like me," and "die-hards."

Participants utilize knowledge from a variety of sources when building a project. They retrieve knowledge with active strategies, such as a Google search, and with passive strategies, such as staying aware of RSS feeds from technology blogs. At times, our participants were working on problems where existing knowledge was not sufficient. In these cases, they sought help via knowledge exchange from personal contacts, both face-to-face and in online communities.

\section{Documenting their Stories}

Projects are rarely documented if they are unsuccessful so, of course, not every project that a hobbyist begins will be documented. Participants gave a range of different reasons when asked why they decided to write a How-To. Some participants spoke specifically about the reaction they hoped it would generate.

I knew the Internet community would be interested and drive traffic to my site - Participant J Other participants felt that given the way they had benefited from the knowledge of others, giving back was the appropriate thing to do. 
Once the project was ready for the public I only felt it normal to share what I had created. - Participant C

Some participants took occasional pictures at various stages of the project, but most of the documentation effort is done after the project is complete. Hobbyists described a translation step between the work itself and the activities that follow in the online domain. Participants created digital artifacts, often after the project was completed, including schematic drawings, pictures, and videos in order to capture their process as a How-To. Roughly half of the participants' personal websites were formatted in the style of a blog, using dated entries that could be filtered by keyword. These websites offered communication features like comments, forums, and chat rooms where readers could interact with the site owner and one another. The rest of the websites used a more traditional homepage style with a "Projects" link that consolidated the How-To information.

Nearly all participants posted their How-To to their personal website, which was rarely dedicated exclusively to the hobbyists' projects. These personal websites contain photos, personal news, and other links of interest to the owner.

I think nowadays it's pretty easy for anyone who wishes to put their work online to do so. ... there are a lot of free tools available for writing docs (openoffice), making diagrams (dia), drawings (the gimp) and so forth. - Participant D

Participants benefit from collecting their project history in a single place. They say the site becomes a reference that they return to when they want to remember what they have done, and it represents the scope of their abilities to new visitors.

I like saving things. It is kind of like an online blog for me and if someone is looking to do the same thing then it is already done and they can do it easier. - Participant A

Participants see their personal website as one of their projects and appreciate the control they have over every aspect of the layout.

Im not so into the whole blog/wiki craze ... I like full control of my code, design, etc. plus the content isn't that dynamic - Participant F

Participants also feel that publishing to a personal website makes their project easier for Google to crawl, consequently making it easier for everyone to find.

The forums are quite niche audiences. If I put it on my website, it receives a MUCH larger audience. Often someone might see something which grabs their attention, and then get interested in that particular aspect of the hobby themselves. And also, the largest proportion of my website visitors come via google searches. Which means they wouldn't find it in a forum. - Participant I

As a place to publish their documentation, forums were seen as more dynamic and more information dense.

I feel like, things get lost in forums - a lot of noise. And if I have something worth saying, usually it's a lot and I don't like trying to fight the noise. I'm usually making something that fills a hole in the internet and if I'm the only thing filling that hole, it'll show up in Google. - Participant B

This participant gives Google an active role in facilitating the discovery of project websites, and that role upholds the values of a meritocracy. The likelihood that 
one's project may be found by Google is perceived to be related to the project's uniqueness and usefulness to others.

The How-To is often written as a story of the project, including how it began, the choices that arose, and how the project has been used since its creation. Consider the following excerpt from the Guitar Hero Controller How-To, which describes a challenge and the subsequent workaround.

At this point we ran into (incredibly) our first major snafu. There was absolutely no place for four AA batteries in here-and of course, you wouldn't want to disassemble it to change them. A quick trip to Batteries Plus netted us a custom-made rechargeable pack made from six 2/3Asized NiMH batteries. They fit along the top side of the main cavity. The remaining pickup bumps into them, however, so we removed the pickup from the cover, cut out the shiny poles, and hot-glued them back into the cover to make a "fake pickup." - How-To Build Your Own Custom Full-Sized Wireless Guitar Hero Controller

Every participant's documentation included pictures, sometimes annotated to draw attention to a specific part of the photograph. Many of the participants used schematic diagrams to illustrate interaction between components or the details in a circuit. About half of these diagrams are hand drawn and scanned, while the other half are created with a software application. Half of the participants used video, hosted specifically on YouTube, to demonstrate the functionality of their projects. Documentation frequently cites specific people who helped with the project and references that the hobbyist used to complete the project. The overwhelming assertion of participants was that content created by other people was always free to make use of but should be referenced with a link to the referring webpage. In practice, participants did not reference every possible piece of related information. The number of links associated with a project's documentation was never more than five.

In documenting their How-To story, participants create knowledge for others to use. The information provided is sequentially structured but varies in a number of ways. Participants take a range of tones to describe their process, some more factual and others more humorous, and use varying levels of detail. Although most How-Tos are published on a personal website, there is a great deal of variation in format, including the use of video, modeling, and diagramming technologies.

\section{Broadcasting their Contributions}

Once the documentation is online, hobbyists want others to see it. An advantage of publishing to a forum is the built-in audience, but when hobbyists use personal websites, they have to create an audience for their work. Several participants were quite attentive to their website traffic, and their "critical mass" gave them confidence that their new content would be found by others.

I guess I just have critical mass that I don't need to get rediscovered each time. - Participant B 
Those who had not established a reputation for their website were explicitly interested in creating one and those pursuing undergraduate degrees believed their websites would represent them favorably to potential employers after graduation.

A quick way to create an audience is to have your project linked from any high-traffic website. In fact, a few participants added "digg this" links to their project webpages. Digg.com is an online community that votes on newsworthy links. One participant whose website averages 40 visitors a day had one of his projects voted to Digg's front page and received 12,000 visitors the next day. We spoke to several participants who had just documented their first project. These participants sent email to several popular blogs when they published their HowTo, hoping that their project would be highlighted by one of the blog editors. One participant spoke of being recognized in this way as his "breakthrough."

You should know that before I got the hack posted, my site was completely unknown. So it was kind of my "breakthrough" ...i couldn't get my hands down when I saw the post on hackaday ... we all like to show off, don't we :) I think it's the global attention and that you display to everybody that you can actually do stuff - Participant G

Other participants agreed that the recognition by blog editors was a validating experience.

Every day I checked hackedgadgets to see what clever projects people have come up with. Then one day I find my own project over there. That makes me kind of proud. - Participant C Being linked to by other websites increases a hobbyist's website traffic significantly and identifies the hobbyist as a contributor.

(someone likened being mentioned on Make is like being "geek Playmate of the Month").

- Participant E

Some participants send a "tip" to the blog editor every time they post a new project, but others establish a reputation they rely on to make their subsequent work visible to others.

We used Google's advanced search to discover the approximate number of websites linking to our participants' websites. Roughly half the participants were linked from more than fifty other websites; the other half were linked by less than ten other websites, if any. In the project documentation cycle, links are used to signify reference material and are rarely used as lists of friends or contacts; this is distinctly different from the way "blogrolls" are used by blog authors. But links from other websites are not the only way to perceive that one's documentation has an audience. Other communication channels are used to send appreciative comments and feedback from readers.

Being recognized as a contributor can expose the hobbyist to a considerable amount of feedback. Feedback comes directly via email or through the comments feature of a referring blog. This feedback is another form of knowledge exchange, and this interaction is sought out by our participants. Many of our participants were vigilant about keeping track of the referring pages when new visitors came to their website and reading all the comments their project received on any referring blog or forum. A few participants implemented a forum or commenting 
features on their website to encourage discussion of their projects; these participants actively moderated these conversations.

if it is not a personal attack I will respond on the site so that it's archived for people to make their own minds up If it's just cursing or some such I delete the comment and do not bother to respond - Participant $\mathrm{H}$

Receiving and responding to feedback is a valued part of the experience, despite the negative feedback our participants reported receiving from readers. Participants, in some cases, attempted to defend or explain themselves when criticized, but none of the participants felt it was a reason to avoid publishing their How-Tos in the future. This feedback is relatively anonymous and participants felt comfortable deciding "the guy obviously doesn't know what he was talking about" when a reader had been critical. Another participant said, "I just laugh at them."

In addition to the public knowledge exchange on the blogs, hobbyists often receive numerous emails. Participants said they were less likely to receive negative feedback over email and more likely to receive questions about technical details. Participants were happy to offer help, in some cases developing friendships with these email contacts and encouraging them to publish their own documentation.

I had one guy who saw my thing on Make, and then he had something that he wanted to make, and he sent me a message and said, "Oh man. I love your thing that I saw, and that makes me want to put my own thing up there." ... and then he submitted to Make and then the next day, it was on. His thing was on there, so that was kind of fun. I talk to him every once in awhile too. - Participant L

One of the most satisfying outcomes of emails for participants was the news that someone else had built their project and personalized or made improvements to it. One participant collected pictures of alternative implementations of his project and published the collection of photos on a separate page on his website.

Since part of my enjoyment comes from other people getting inspired. It's flattering if someone builds one of my projects. - Participant I

While the number of comments on forums and blogs peaks and then tapers off, participants report receiving and responding to email for some time, in one case years after the How-To was published.

For hobbyists, broadcasting their contribution is critical if they want to participate in knowledge exchange about their completed work. Our participants sought feedback from other hobbyists by sending their How-Tos to blog editors, but they were also proud of helping other hobbyists over email. Hobbyists broadcast their contribution in order to participate in knowledge exchange, the sort of exchange they participated in while the project was being built. 


\section{Discussion}

As a class of online content, our research characterizes the How-To as a flexible format; we observed a variety of approaches to the implementation of How-Tos. We have already commented that documenting procedural knowledge in textbased media is a challenge, as previously identified by Pipek and Wulf (2003). Hobbyists rise to this challenge by leveraging a variety of media. A mix of photos, video, drawings, and text are arranged to create a presentation of the hobbyist's process. This sophisticated use of multimedia is only beginning to show up in studies of organizational knowledge management (Grudin, 2006) but is clearly worthy of further investigation.

In addition to the form of the How-To, our research explored the practices surrounding its use. Among our sample of computer and electronics hobbyists, the creation of a How-To is one phase of their knowledge sharing activities. While hobbyists' physical work is largely accomplished alone, social interaction is interleaved throughout. We observed an informal system of knowledge sharing that makes use of multiple communication technologies to connect to different communities. Blogs provide awareness of what other hobbyists are doing. So when a hobbyist's How-To is linked by a blog, the hobbyist's contribution is broadcast and reputation is strengthened. Hobbyists use search engines to directly seek out other hobbyists' How-Tos and may communicate with their authors over email. In the same fashion, hobbyists respond to email they receive regarding their own How-Tos. Finally, hobbyists participate in forums and newsgroups, as well as face-to-face communities; these contacts are valuable resources when hobbyists encounter particularly difficult problems. Our participants had very few complaints about the tools they used or about the How-To sharing process. This evolving, interdependent system of communication tools is acceptable, even satisfying, for our participants.

On the surface, the informal system of How-To sharing we have described bears little resemblance to traditional knowledge management applications, an issue of longstanding interest in the CSCW community. Previous research has focused largely on organizational settings while, of course, How-To sharing exists in a broad, decentralized system of volunteers. Knowledge management tools are frequently an attempt to consolidate knowledge content; as such, they often take the shape of a single application. As we have described it, How-To sharing occurs within and across a collection of communication tools without any centralized control. While acknowledging these important differences, we propose that HowTo sharing can be usefully described as an expertise-location system; a hobbyist's collection of How-Tos functions much like a user profile in an expertise-location system.

Early knowledge management systems were repositories for documents or other knowledge content. Expertise-location systems build on this work by 
connecting people to one another in order to leverage social interactions as a mode of knowledge transfer. An expertise-location system recommends an appropriate person to contact for help in a given area (e.g., Streeter and Lochbaum, 1988; McDonald and Ackerman, 1998; Reichling and Veith, 2005; Pipek and Wulf, 2003). While an expertise-location system uses profiles to match individuals, the hobbyists we observed make use of other hobbyists' How-Tos. The How-To documentation of various projects is an advertisement for hobbyists' areas of expertise. Other hobbyists then use available contact information to seek out this expertise through direct communication.

The combination of explicit knowledge representation in the How-To and the surrounding communications is mirrored in previous systems like the Answer Garden (Ackerman, 1994; Ackerman and McDonald, 1996). In both the Answer Garden and How-To sharing, experts document knowledge for reuse but engage in further communications when necessary. The Answer Garden allows users to communicate with experts directly through the system. In the context of How-To sharing, our participants communicated through both public and private communication channels. A discussion on a public forum, blog, or personal website is archived indefinitely, so the conversation is available for later readers. Private channels like email were also used, frequently by novice hobbyists. These newcomers to the community may prefer to keep their communications private while they gain experience.

In the remainder of the discussion, we continue to explore How-To sharing as an informal instance of an expertise-location system. First, we discuss how our participants met the primary challenge of finding the right expert using a combination of active and passive strategies. Second, we discuss another challenge for expertise-location systems, motivating the experts. We highlight the unique qualities of the How-To, as both a hobbyist's portfolio and personal history, that appear to motivate participation by experts.

\section{Encountering and Searching for How-Tos}

Our study of hobbyists' practices illustrates the importance of a diversity of tools. We observed computer and electronics hobbyists adopting a diverse set of technologies to leverage the unique capabilities of each tool. Similar to the findings of McDonald and Ackerman (1998), we found that our participants balance purposeful expertise seeking strategies with a general awareness of their environment. In addition to strategically using Google to search for How-Tos, our participants engage in more passive ways of encountering How-To information.

RSS (Real Simple Syndication) is a rather rudimentary event notification technology that polls a web server to see if there is something new. Our participants scan RSS feeds from blogs and other hobbyists' websites for headlines that interest them. By staying aware of what other hobbyists are doing, 
they gather information before they even recognize the need for it. The way event notification is adopted and used in organizations has been relevant to CSCW (Fitzpatrick et al., 1999). However, the implications of event notification technologies for identifying expertise have not specifically been addressed. In this case, we saw that RSS provides hobbyists with general technology-related information, as well as introduces them to other hobbyists' activities.

Hacking-related blogs are a primary source of our participants' RSS feeds. On these blogs, an editor highlights specific projects by commenting on a project and linking to the project website. These blog editors fulfill an important role in the system because they become gatekeepers to a much larger collection of projects a hobbyist might not otherwise encounter. The role of the information gatekeeper has been recognized in a number of knowledge sharing systems (e.g. Paepcke, 1996; Erlich and Cash, 1994; McDonald and Ackerman, 1998). In addition to mediating information for hobbyists, the opinions of blog editors are a central way of validating hobbyists' contributions. Hobbyists admire the hacks posted to these blogs and want to be similarly acknowledged and admired; they want to be a part of that blog's community.

\section{How-Tos as Portfolio and Personal History}

Participants clearly understand that the online representation of their project is a representation of who they are and what they know - a presentation of self. This finding is similar to system deployment and adoption studies where organizational participants were required to create their own expertise profiles (e.g., Streeter and Lochbaum, 1988; Maybury, D'Amore and House, 2003). But unlike some organizational settings where individuals may resist the time and effort necessary to maintain a profile, hobbyists create and maintain project documentation as a contribution to the broader community and as an artifact that benefits them personally.

Participants talk about their collection of How-Tos as a portfolio. Students, in particular, mentioned the benefit of displaying one's prior work to potential employers. So while participants believe other hobbyists can infer their expertise from their How-Tos, they are also aware of their visibility to the larger population. This visibility has benefits, including the benefit of presenting oneself well to potential employers.

Participants believe their portfolio of work will help other hobbyists and will reflect well on them to potential employers, but they do not disregard the direct benefit they receive from documenting their work. Participants talked about their How-Tos as diaries, as references for the future when they could no longer remember their process, and as a history of their interactions with others. Participants post FAQs and pictures of other hobbyists' implementations of their 
projects. The How-To is often coupled to its reaction from the larger community and serves as a record of the influence of that project.

Given the motivations of these hobbyists, it comes as no surprise that nearly all of our participants created their websites from scratch. They have specific needs in representing their portfolio to others and in recording their activities for themselves. As such, their website became a project in and of itself; hobbyists' websites are personal expressions. Some participants said they found it motivating to create their own online space. Once it was created, it motivated them to continue doing the difficult work of documenting their How-Tos.

\section{Implications of How-To Sharing}

These results have important implications for expertise-location systems. These results reinforce the importance of fostering person-to-person expertise exchange, like that in Answer Garden (Ackerman, 1994; Ackerman and McDonald, 1996; Pipek and Wulf 2003) and the Expertise Recommender (McDonald and Ackerman, 2000; McDonald, 2003). It is rare for a hobbyist to develop a project without some form of individual interaction with another person, even if the physical work was largely solo.

Expertise-location systems need to support awareness as well as purposeful search for others' expertise. We propose that readers of How-Tos can make inferences about the author's expertise. This proposal should be tested in future work, but it remains an interesting possibility for the maintenance of expertise profiles. Rather than asking people to make their skills and areas of expertise explicit, perhaps expertise can be inferred from a portfolio-style profile. Diverse sources of work and work by-products might be used to create the representation of an individual's expertise.

As younger generations of workers join organizations, generations of workers who grew up with MySpace, Friendster or one of the many other profile-based social networking sites, we may find less reluctance to maintain professional online representation. We see these portfolios as distinctly different from an explicitly articulated profile; one where the individual maintains control and which represents work, perhaps from more than one organization, of which the individual is proud. The creation of a portfolio is motivating because it becomes a resource for the worker as well as for the greater community.

\section{Conclusion}

This research explored the collaborative aspects of procedural knowledge sharing by computer and electronics hobbyists through the lens of the How-To. Rather than focusing our inquiry on a single website, or a single communication technology, we investigated the knowledge sharing activities of hobbyists. Our 
participants work from different parts of the world with a range of different devices and technologies, and there is no central organization that codifies their behavior. Our participants created diverse examples of How-To content, yet the practices surrounding the How-To, knowledge retrieval, knowledge creation, and knowledge exchange, were surprisingly similar.

By investigating the knowledge sharing activities involved in building a project, documenting a story, and broadcasting a contribution, we observed a system of knowledge sharing comparable to previous research in expertise location. In its creation, the How-To is a record of its author's activities and expertise. In its publication, the How-To is a way to share this expertise and connect with other hobbyists. The unique qualities of How-To sharing present opportunities for the development of knowledge sharing systems in the emerging technological landscape.

\section{Acknowledgements}

This research was initiated with the support of a summer internship with Intel Corporation and was continued with the support of National Science Foundation grants IIS-0121426 and IIS-0624275. We would like to thank Jeremy Goecks, Laura Dabbish, Sara Kiesler, and Susan Fussell for their thoughtful comments on this work.

\section{References}

Ackerman, M. S. (1994): 'Augmenting the Organizational Memory: A Field Study of Answer Garden', in Proceedings of the 1994 ACM Conference on Computer-Supported Cooperative Work (CSCW '94), pp. 243-252.

Ackerman, M. S. and McDonald, D. W. (1996): 'Answer Garden 2: Merging Organizational Memory with Collaborative Help', in Proceedings of the 1996 ACM Conference on Computer Supported Cooperative Work (CSCW'96), pp. 97-105.

Ehrlich, K. and Cash, D. (1994): 'Turning Information into Knowledge: Information Finding as a Collaborative Activity', in Proceedings of Digital Libraries '94, pp. 119-125.

Fitzpatrick, G., Mansfield, T., Kaplan, S., Arnold, D., Phelps, T., and Segal, B. (1999): 'Augmenting the everyday world with Elvin', in Proceedings of the 6th European Conference on Computer Supported Cooperative Work (ECSCW '99), pp. 431-450.

Goldfayn, A.L. (2007): 'Make something: Magazine bucks trend by building devoted audience', Chicago Tribune, February 5, 2007.

Grudin, J. (2006): 'Enterprise Knowledge Management and Emerging Technologies', in Proceedings of the 39th Hawaii International Conference on System Sciences, (HICSS '06).

Halverson, C., Erickson, T. and Ackerman, M. (2004): 'Behind the Help Desk: Evolution of a Knowledge Management System in a Large Organization', in Proceedings of the ACM Conference on Computer Supported Cooperative Work (CSCW '04), Chicago, IL, pp. 304313. 
Hinds, P.J. and Pfeffer, J. (2003): "Why Organizations Don't "Know What They Know": Cognitive and Motivational Factors Affecting the Transfer of Expertise', in M. Ackerman, V. Pipek, and V. Wulf (eds.): Sharing Expertise: Beyond Knowledge Management, MIT Press, Cambridge, 2003, pp. 111-136.

Huysman, M.H. and de Wit, D. (2003): 'A Critical Evaluation of Knowledge Management Practice', in M. Ackerman, V. Pipek, and V. Wulf (eds.): Sharing Expertise: Beyond Knowledge Management, MIT Press, Cambridge, 2003, pp. 111-136.

Leonard, D. and Sensiper, S. (1998): 'The Role of Tacit Knowledge in Group Innovation', California Management Review, vol. 40, no. 3, pp. 112-132.

Maybury, M., D'Amore, R. and House, D. (2003): 'Automated Discovery and Mapping of Expertise', in M. Ackerman, V. Pipek, and V. Wulf (eds.): Sharing Expertise: Beyond Knowledge Management, MIT Press, Cambridge, 2003, 359-382.

McDonald, D. W. and Ackerman, M. S. (1998): 'Just Talk to Me: A Field Study of Expertise Location', in Proceedings of the 1998 ACM Conference on Computer-Supported Cooperative Work (CSCW'98), pp. 315-324.

McDonald, D. W. and Ackerman, M. S. (2000): 'Expertise Recommender: A Flexible Recommendation System and Architecture', in Proceedings of the 2000 ACM Conference on Computer-Supported Cooperative Work (CSCW '00), pp. 231-240.

McDonald, D. W. (2003): 'Recommending Collaboration with Social Networks: A Comparative Evaluation', in Proceedings of the 2003 ACM Conference on Human Factors in Computing System (CHI '03), pp. 593-600.

Paepcke, A. (1996): 'Information Needs in Technical Work Settings and Their Implications for the Design of Computer Tools', Computer Supported Cooperative Work: The Journal of Collaborative Computing, vol. 5, pp. 63-92.

Pipek, V. and Wulf, V. (2003): 'Pruning the Answer Garden: Knowledge Sharing in Maintenance Engineering', in Proceedings of the 8th European Conference on Computer Supported Cooperative Work (ECSCW '03), pp. 1-20.

Reichling, T. and Veith, M. (2005): 'Expertise Sharing in a Heterogeneous Organizational Environment', in Proceedings of The 9th European Conference on Computer-Supported Cooperative Work, (ECSCW '05), pp. 325-345.

Spender, J.C. (1996): 'Competitive Advantage from Tacit Knowledge? Unpacking the Concept and its Strategic Implications', in B. Mosingeon and A. Edmonson, (eds.): Organizational Learning and Competitive Advantage, Sage Publications, London, 1996, pp. 56-73.

Streeter, L. A. and Lochbaum, K. E. (1988): 'Who Knows: A System Based on Automatic Representation of Semantic Structure', in Proceedings of RIAO '88, pp. 380-388.

Voida, A., Mynatt, E.D., Erickson, T., and Kellogg, W.A. (2004): 'Interviewing over instant messaging', in extended abstracts of the ACM SIGCHI Conference on Human Factors in Computing Systems (CHI ‘04). Vienna, Austria, pp. 1344-1347. 